\title{
Evidence of Plasmonic Induced Photocatalytic Hydrogen Production on Pd/TiO 2 Upon Deposition on Thin Films of Gold
}

\author{
M. A. Khan ${ }^{1} \cdot$ L. Sinatra ${ }^{2} \cdot$ M. Oufi ${ }^{1}$ O. M. Bakr ${ }^{2} \cdot$ H. Idriss ${ }^{1,3}$
}

Received: 1 January 2017 / Accepted: 13 February 2017 / Published online: 28 February 2017

(C) The Author(s) 2017. This article is published with open access at Springerlink.com

\begin{abstract}
H}_{2}$-production from renewables using sunlight is probably the holy grail of modern science and technology. Among the many approaches for increasing reaction rates, by increasing light absorption, plasmonic materials are often invoked. Yet, most plasmonic metals on semiconductors are also good for Schottky barrier formation. In this work, we are presenting evidences of de-coupling the plasmonic from Schottky effects on photoreaction. To conduct this we have systematically changed the under-layer gold film thickness and associated particle size. On top of the thin film layer, we have deposited the exact amount of a prototypical Schottky-based photo-catalyst $\left(\mathrm{Pd} / \mathrm{TiO}_{2}\right)$. We found up to 4 times increase in the $\mathrm{H}_{2}$-production rate at a critical Au film thickness ( $8 \mathrm{~nm}$-thick). Below this thickness, the plasmonic response is not too strong while above it, the PR decays in favor of the Drude absorption mode. The reaction requires the presence of both UV (to excite the semiconductor) and visible light (to excite Au particles) in order to obtain high hydrogen production, $800 \mu \mathrm{mol} / \mathrm{g}_{\text {Catal }}$. min (probably the highest direct hydrogen (not current) production rate reported on a performing catalyst). The enhancement origin is quantitatively traced to its computed
\end{abstract}

Electronic supplementary material The online version of this article (doi:10.1007/s10562-017-1998-4) contains supplementary material, which is available to authorized users.

\section{H. Idriss}

IdrissH@SABIC.com; h.idriss@ucl.ac.uk

1 SABIC Corporate Research and Development (CRD), KAUST, Thuwal, Saudi Arabia

2 Solar and Photovoltaic Research Center, KAUST, Thuwal, Saudi Arabia

3 Department of Chemistry, University College London, Gordon Street, London, UK electric field strength (EFS). Adding a dielectric $\left(\mathrm{SiO}_{2}\right)$ in between the Au thin layer and the catalyst exponentially decreased the reaction rate and EFS, with increasing its thickness. This work indicates the possibility of making an active and stable photo-catalyst from fundamental concepts yet further progress on the structural (technological) front is needed to make a practical catalyst.

\section{Graphical abstract}

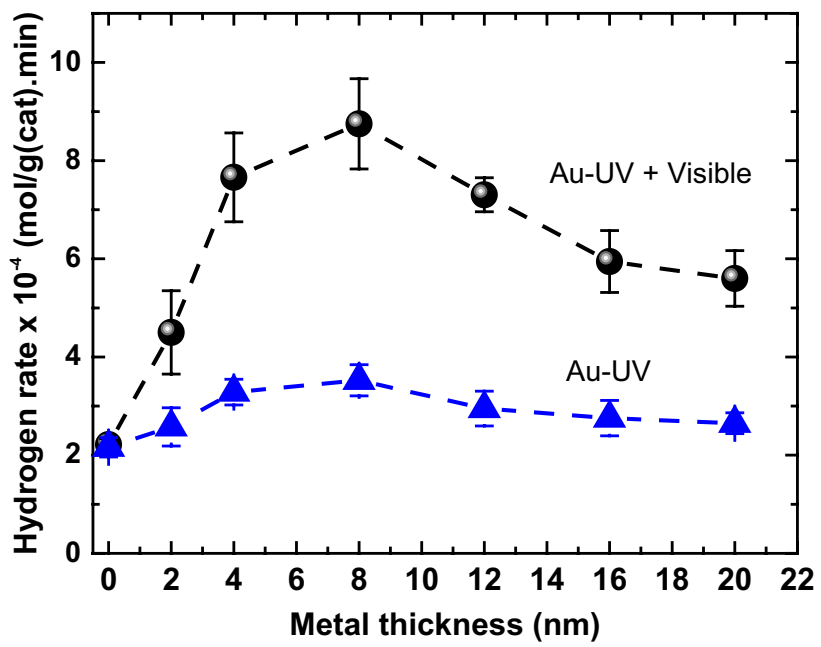

Keywords Photocatalysis · Hydrogen production · Gold plasmon $\cdot \mathrm{Pd} / \mathrm{TiO}_{2} \cdot$ Electric field enhancement

\section{Introduction}

From the very first report of Fujishima and Honda, $\mathrm{TiO}_{2}$ has been widely regarded as the leading candidate for solar $\mathrm{H}_{2}$ production because of its excellent stability [1]. Nonetheless, $\mathrm{TiO}_{2}$ suffers from low solar to $\mathrm{H}_{2}$ conversion 
efficiency because of high charge carrier recombination and limited light absorption $(<400 \mathrm{~nm})$. Over the past decades, plasmonic properties of metal nanoparticles such as $\mathrm{Au}$ and Ag have come into focus as promising methods to further improve current efficiencies [2-4]. Localized surface plasmons resonance (LSPR) are oscillations of free electrons that are confined to the surface of these nanoparticles. At resonance, the charge oscillations create an intense local electric field (EF) at the surface of these nanoparticles. There have been several studies reporting plasmonic enhanced photocatalytic activity of $\mathrm{TiO}_{2}$ by using $\mathrm{Au}$ and $\mathrm{Ag}$ nanoparticles [5-8]. Yet these enhancements are either mild or could not be proven independently. In that regard, $\mathrm{TiO}_{2}$ has been studied in various forms such as nanoparticles, core shell structure and thin films with $\mathrm{Au}$ and $\mathrm{Ag}$ nanoparticles to unravel the major mechanisms involved in plasmonic photocatalysis and to provide physical explanations for enhanced activities [7,9]. The mechanism by which plasmonic metal nanoparticles improve energy conversion maybe grouped in two categories as follows:[2, 3].

i. Photonic enhancement to increase light absorption through

(a) Far field scattering or

(b) Near field enhancement by localizing the electromagnetic (EM) field.

ii. Plasmon energy transfer by increasing local generation of electron hole pairs through

(a) Direct electron transfer (DET) via hot electrons or

(b) Resonant energy transfer (RET) which directly excites electron-hole pairs non-radiatively through the relaxation of the surface plasmon dipole.

A number of reports have used one or more of these possible pathways to explain the observed enhancement but the understanding needed for the design of a practical catalytic material and of the dominant enhancement mechanism is still ambiguous [3]. Previous studies on determining the LSPR enhanced mechanism have placed metal nanoparticles on the surface of the semiconductor as a co-catalyst. Yet, all reported observed enhancements do not show higher activity than non-plasmonic metals (Pt, and Pd metals, typically $1-3 \mathrm{~nm}$ in size), at similar metal loading, therefore it is not clear if this enhancement is due to plasmonic effect or simply due to the presence of the metal as an electron sink (Schottky barrier). Unambiguously resolving the dominant energy transfer mechanism requires the design of controllable metal/SC composite nanostructures which in turn is needed for making a practical photo-catalyst.

In this study, we have investigated the photocatalytic $\mathrm{H}_{2}$ production activity of $0.4 \mathrm{wt} \% \mathrm{Pd} / \mathrm{TiO}_{2}$ photocatalyst coated on top of ultra-thin plasmonic gold films with different film thickness from water-glycerol mixtures. We observed very high enhancements in the hydrogen production rate $(4 \mathrm{x})$ upon putting an ultra-thin Au film underneath the $\mathrm{TiO}_{2}$ photocatalyst. Also, we have found a direct corelation between the trends of electric field (EF) enhancement of the Au films and the photocatalytic activity of the $\mathrm{TiO}_{2}$ coated on top. It is important to mention that while large bodies of reports indicate rate enhancements, most are based on current measurements which may not be quantitatively translated to real hydrogen production. Equally important we found that upon transition from plasmonic to non-plasmonic response of the Au thin film after forming a continuous film, the enhancement of the reaction rates considerably decreases.

\section{Methods}

Catalysts were prepared as follows. Anatase $\mathrm{TiO}_{2}$ (commercial Hombikat UV 100 produced by Huntsman - formerly Sachtleben Chemie) with an average particle size of $\sim 7 \mathrm{~nm}$ (measured using TEM) and initial BET surface area $\sim 320 \mathrm{~m}^{2} / \mathrm{g}$ was impregnated with $\mathrm{PdCl}_{2}$ salt solution (in $1.87 \mathrm{M} \mathrm{HCl}$ ). Excess water was evaporated to dryness under constant stirring with slow heating at $80{ }^{\circ} \mathrm{C}$. The dried photocatalysts were calcined at $350^{\circ} \mathrm{C}$ for $4 \mathrm{~h}$. The resulting $0.4 \mathrm{wt} \% \mathrm{Pd} / \mathrm{TiO}_{2}$ photocatalyst had an average particle size of $\sim 10-12 \mathrm{~nm}$ (TEM) and BET surface area of $\sim 120 \mathrm{~m}^{2} / \mathrm{g}$. Microscopic glass slides were cleaned by ultrasonication in acetone, ethanol then DI water. Thin Au films were deposited on these glass slides by thermal evaporation (Sigma Aldrich, Purity of 99.999\%) in a vacuum chamber at a base pressure $1 \times 10^{6}$ Torr (Angstrom Engineering). The deposition was done at room temperature with a constant rate of $0.2 \mathrm{~A} \%$ monitored using a quartz crystal monitor. The $\mathrm{SiO}_{2}$ deposition was done using a PECVD (Plasma Enhanced Chemical Vapor Deposition) tool at an RF power of $10 \mathrm{~W}$, substrate temperature of $300^{\circ} \mathrm{C}$ and a controlled flow of $\mathrm{SiH}_{4}, \mathrm{~N}_{2} \mathrm{O}$ and $\mathrm{N}_{2}$ gases. The $\mathrm{Pd} / \mathrm{TiO}_{2}$ photocatalysts were deposited on the Au thin films by spin coating. A $1.5 \mathrm{wt} \%$ dispersion was prepared in ethanol and spun coated on the Au thin film at $500 \mathrm{rpm}$ for $20 \mathrm{~s}$. The coating was repeated 5 times and the thin films were heated at $90{ }^{\circ} \mathrm{C}$ for $20 \mathrm{~min}$, to remove ethanol, and the resulting thickness of the photocatalyst layer was $<1 \mu \mathrm{m}$ as measured by cross section SEM analysis.

UV-Vis absorbance spectra of the powdered catalysts were collected over the wavelength range of 250-2000 nm 
on a Thermo Fisher Scientific spectrophotometer equipped with praying mantis diffuse reflectance accessory. Absorbance (A) and reflectance (\% R) of the samples were measured. BET surface areas of catalysts were measured using Quantachrome Autosorb analyzer by $\mathrm{N}_{2}$ adsorption. Photocatalytic reactions were evaluated in a $190 \mathrm{~mL}$ volume quartz reactor. $30 \mathrm{~mL}$ of $5 \mathrm{vol} \%$ glycerol aqueous solution was used to evaluate the water splitting activity. The coated slides were inserted vertically into the reactor and the reactor was purged with $\mathrm{N}_{2}$ gas to remove any molecu$\operatorname{lar} \mathrm{O}_{2}$. Photoreactions were carried out using a Xenon lamp (Asahi spectra MAX-303) at a distance of $9 \mathrm{~cm}$ from the reactor with a UV flux $(320-400 \mathrm{~nm})$ of $\sim 12 \mathrm{~mW} / \mathrm{cm}^{2}$ and visible flux $(400-700 \mathrm{~nm})$ of $\sim 97 \mathrm{~mW} / \mathrm{cm}^{2}$, as measured with a spectro-radiometer (Spectral Evolution SR-500). Product analysis was performed by gas chromatograph (GC) equipped with thermal conductivity detector (TCD) connected to Porapak Q packed column ( $2 \mathrm{~m}$ long, 1/8 in. external diameter) at $45{ }^{\circ} \mathrm{C}$ and $\mathrm{N}_{2}$ was used as a carrier gas (Flow rate of $20 \mathrm{~mL} / \mathrm{min}$ ). We, and others, have studied the reaction products during photocatalytic reforming of alcohols which ultimately results in hydrogen and $\mathrm{CO}_{2}$ formation as the final reaction products [10-15].

Optical simulations were carried out using COMSOL Multiphysics code which uses finite element method (FEM) to solve Maxwell's equations and gives electrical field intensity $\left(|\mathrm{E}|^{2}\right)$ as an output. The incident electromagnetic field was put at $1 \mathrm{~V} / \mathrm{m}$, with wavelength set to be at 500 or $350 \mathrm{~nm}$ and polarized in the y-direction. The incident electromagnetic field is assumed to be normal to the Au films or glass substrate. Dielectric permittivity of Au was taken from Johnson-Christy report and the Au particle size for 2 and $4 \mathrm{~nm} \mathrm{Au}$ films was taken from the SEM images from Fig. 1 while continuous films were assumed for $8,12,16$ and $20 \mathrm{~nm}$ thickness. $\mathrm{TiO}_{2}$ particle size is taken equal to $10 \mathrm{~nm}$.

\section{Results and Discussion}

Figure 1a shows high resolution scanning electron microscopy (HRSEM) images of ultra-thin Au films with thicknesses between 2 and $20 \mathrm{~nm}$ deposited on quartz slides. At initial stages of film growth, isolated 3D metal islands are formed on the substrate surface, instead of continuous metal film as evident in 2 and $4 \mathrm{~nm}$ thick Au films. With increasing thickness, these islands exhibit coalescence of $\mathrm{Au}$ NPs to larger ones with a high coverage on the substrate and a continuous film is eventually formed by $\sim 12 \mathrm{~nm}$. This growth mechanism has been experimentally observed in other studies $[16,17]$. This island-like structure of ultrathin film of Au leads to some interesting optical properties. Figure $1 \mathrm{~b}$ shows the absorption spectra of Au thin films as a function of thickness. A difference in the film thickness can be translated to differences in the particle size, shape and inter particle distance; all changes the absorption properties. As seen in Fig. 1b there are three absorption regions. Peaks observed at $\sim 260$ and $380 \mathrm{~nm}$ are attributed to the inter-band transitions from $d$ valance band to the empty states in the $\mathrm{s}$ and $\mathrm{p}$ bands above Au Fermi level. The LSPR for $2 \mathrm{~nm} \mathrm{Au}$ film thickness is located around $570 \mathrm{~nm}$, it is red shifted with increasing thickness up to $8 \mathrm{~nm}$. The red shift for LSPR peaks tracks the increase in Au particle size, observed in our SEM images. This is due to a reduction in oscillation of electrons resulting from the reduction of restoring force associated with inhomogeneous polarizations in a particle with large size and irregular shape. For films thicker than $8 \mathrm{~nm}$, the formation of interlinks (conductive percolation paths) between the Au NPs due to their aggregation can delocalize the free electrons inside the particles making the Drude absorption more significant and suppresses the LSPR of the Au NPs. Similar trends have been observed for $\mathrm{Au}$ and $\mathrm{Ag}$ thin films in other studies [17]. A statistical analysis of the Au particle size and frequency distribution was done using AFM topography measurements (See S3a supplementary information). Figure 2 shows the statistical distribution of particle size for 2, 4 and $8 \mathrm{~nm}$ thick films respectively after which a continuous film is formed. The average particle for $2 \mathrm{~nm}$ film is $\sim 13.5 \mathrm{~nm}$ and increases upto $\sim 35-50 \mathrm{~nm}$ for $8 \mathrm{~nm}$ film with a broader distribution.

The photocatalytic activity of $0.4 \mathrm{wt} . \% \mathrm{Pd} / \mathrm{TiO}_{2}$ films coated on top of the Au films was studied under UV and visible light excitation and the $\mathrm{H}_{2}$ production rates are presented in Fig. 3. We conducted the work under UV to only excite the semiconductor and under UV + Vis light to excite both the semiconductor and Au nanoparticles. No activity was seen when we used visible light alone. For all runs discussed next, amount and thickness of $\mathrm{TiO}_{2}$ photocatalyst was kept constant and the activity was stable and reproducible. It is also to be noted that we are not working in a saturation regime i.e., using very thin catalyst coatings to optimize the plasmonic response on the catalytic material. Also, to de-convolute the effect of the $\mathrm{Au}$ thin film underneath, the light is irradiated onto the semiconductor layer on top making sure identical number of photons being absorbed by the photo-catalyst on top of the Au layer. Pure anatase $\mathrm{TiO}_{2}$ with $0.4 \mathrm{wt} \% \mathrm{Pd}$ loading, showed $\mathrm{H}_{2}$ production rates of $\sim 200 \mu \mathrm{molg}^{-1} \mathrm{~min}^{-1}$. When the same amount of catalyst was coated on $\mathrm{Au}$ thin films, it showed a considerable increase in the $\mathrm{H}_{2}$ production rates. With $2 \mathrm{~nm}$, Au underneath the photocatalyst $\mathrm{H}_{2}$ production rate increased 2.5 times to $\sim 550$ $\mu$ molg ${ }^{-1} \mathrm{~min}^{-1}$. With increasing $\mathrm{Au}$, thin film thickness the reaction rates kept improving with maximum $\mathrm{H}_{2}$ rate for $8 \mathrm{~nm} \mathrm{Au}$ films of $\sim 850 \mu \mathrm{molg}^{-1} \mathrm{~min}^{-1}$. Further 
(a)
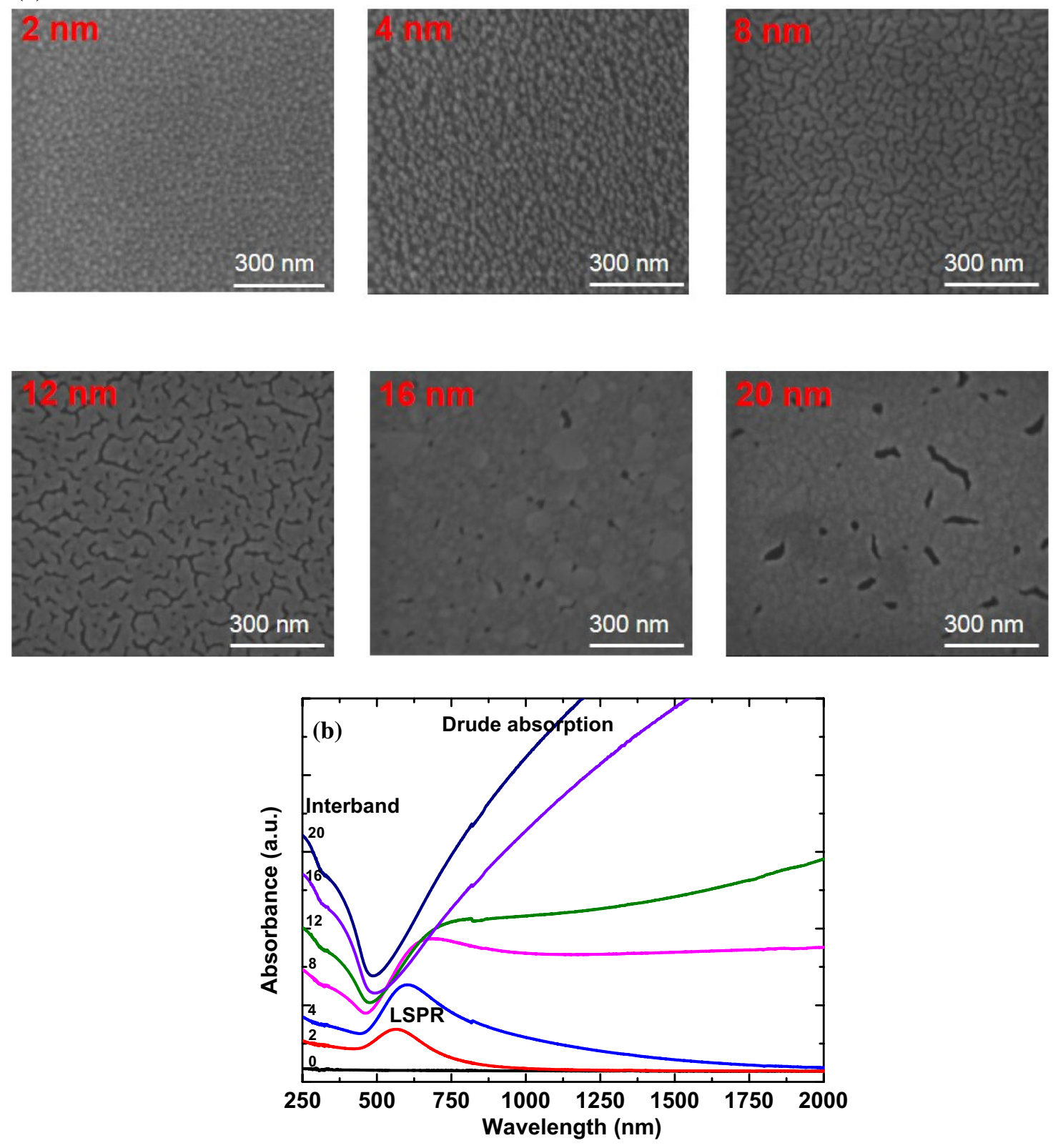

Fig. 1 a High Resolution SEM images of Au thin films $(2-20 \mathrm{~nm})$ thermally evaporated on quartz slides (deposition rate of $0.2 \mathrm{~A} / \mathrm{s}$ and at a pressure of $1 \times 10^{-6}$ torr), b UV-Vis-IR absorbance spectra of Au thin films with different thickness (in nm) on quartz slides

increase in the thickness of underlying Au thin film led to a decrease in activity as seen for films from 12 to $20 \mathrm{~nm}$ thickness. The trend in $\mathrm{H}_{2}$ production was similar to the trend seen in LSPR from these Au films as discussed in Fig. 1 where for film thickness greater than $8 \mathrm{~nm}$, the LSPR started to be suppressed due to the Drude absorption. Normalizing the rates to area of the LSPR peaks, showed linear $\mathrm{H}_{2}$ production as function of Au thickness as seen in Fig. 3a, within experimental errors, giving quantitative evidence for the improvement in activity; due to the LSPR of Au.
In another set of experiments, we have changed (1) the light frequency and (2) replaced Au by Pt (a non plasmonic metal in these conditions). (1) By cutting of the visible light, we can further check for the LSPR effect. As seen in Fig. $3 \mathrm{~b}$ the activity under UV light $(<400 \mathrm{~nm})$ was much lower. It is to be noted that the trend of rates under UV is the same with maximum activity for $8 \mathrm{~nm} \mathrm{Au}$ at $\sim 380$ $\mu$ molg ${ }^{-1} \min ^{-1}$. (2) Pt metal (non plasmonic) was deposited with different thicknesses; Fig. $3 c$ presents its absorbance spectra. There is no LSPR peaks present with only Drude absorption seen for thicker films (15 and $20 \mathrm{~nm}$ ). The exact 

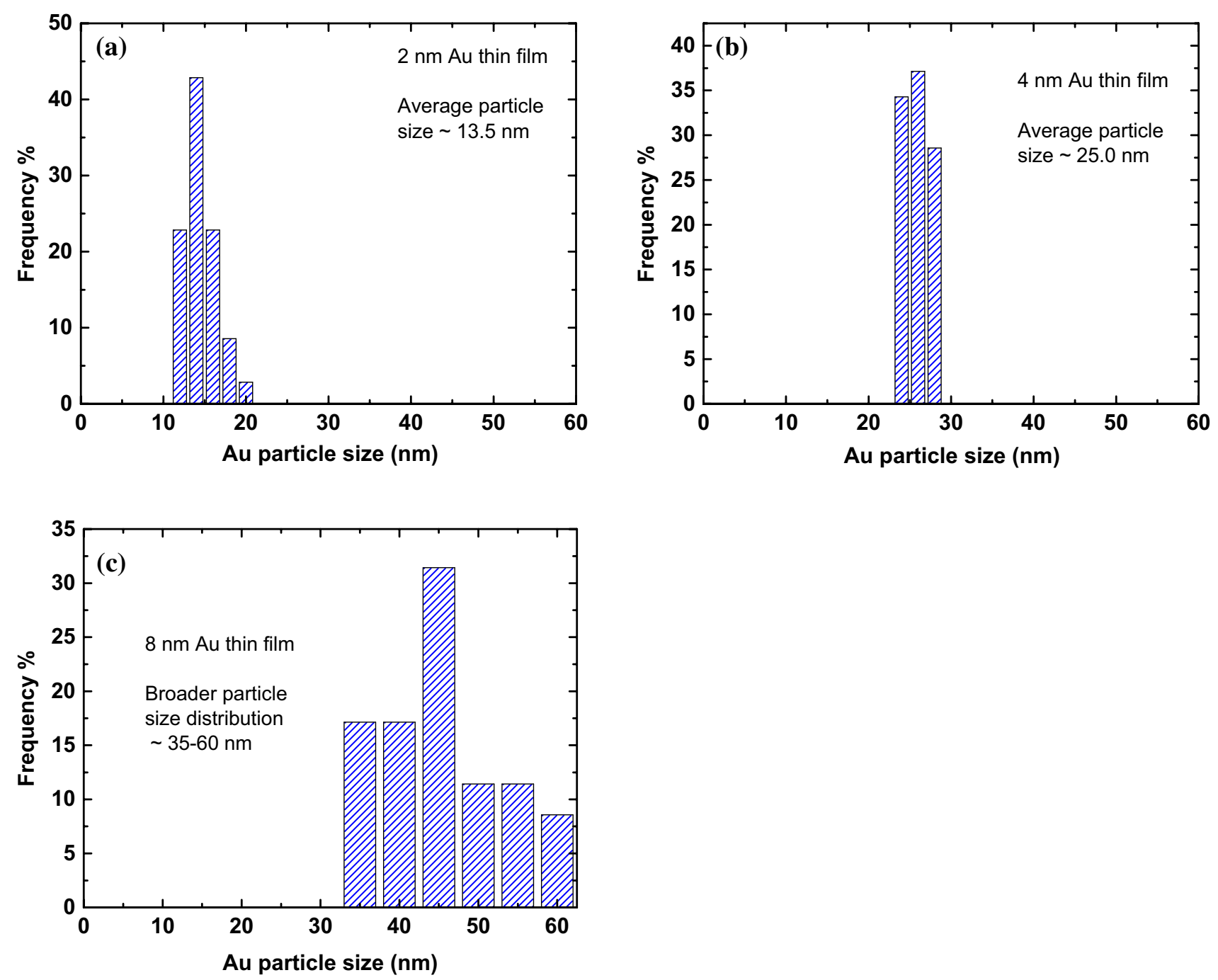

Fig. 2 Particle size distribution of 2, 4 and $8 \mathrm{~nm}$ thick (a-c) Au thin films thermally evaporated on quartz slides (deposition rate of $0.2 \mathrm{~A} / \mathrm{s}$ and at a pressure of $1 \times 10^{-6}$ torr). Analysis was done using AFM topography images (See supplementary figure S3a)

amount of $0.4 \mathrm{wt} . \% \mathrm{Pd} / \mathrm{TiO}_{2}$ photocatalyst was then coated on top of Pt similar to the Au system and photocatalytic activity was measured under identical conditions. A small increase in $\mathrm{H}_{2}$ production rates after adding $\mathrm{Pt}$ thin film up to $310 \mu \mathrm{molg}^{-1} \mathrm{~min}^{-1}$ for $20 \mathrm{~nm}$ Pt films. The difference in $\mathrm{H}_{2}$ production rates from $\mathrm{Au}$ and $\mathrm{Pt}$ films is also highlighted in Fig. 3d where the activity using Au films is $\sim 4$ times higher. In other words, one can conclude that the interface between $\mathrm{Pt}$ thin film and $\mathrm{Pd} / \mathrm{TiO}_{2}$ has minor effect when compared to that of Au thin film.

To further probe into the role of LSPR we performed optical simulations of $\mathrm{TiO}_{2}$ on $\mathrm{Au}$ films by using COMSOL Multiphysics code which uses finite element method (FEM) to solve Maxwell's equations and gives electrical field intensity $\left(|E|^{2}\right)$ as an output. Details on the simulations can be found in the experimental section and supplementary information. The results are presented in Fig. 4.
Data of the EF enhancements for different Au thickness are given in Fig. 5a. With $2 \mathrm{~nm}$ Au film, the enhancement is found to be $\sim 5$ times at the surface of $\mathrm{TiO}_{2}$ particle. Increasing $\mathrm{Au}$ film thickness improved the EF enhancement up to 19 times for $8 \mathrm{~nm}$ films and then starts dropping for thicker films. This was observed in both $\mathrm{XY}$ and $\mathrm{YZ}$ planes as seen in Fig. 5a. The field intensity strongly depends on the geometry i.e. size, shape and inter-particle distance between the metal nanoparticles. The enhancement is known to increase up to a $10^{4}$ times if the inter particle distance is less than $2 \mathrm{~nm}$ and the area between these metal particles are known as "plasmonic hot spots"[18 ]. With increasing thickness of Au thin films, the Au islands grow in size and the inter particle distance decreases before becoming a continuous film. The maximum EF enhancement is seen at the point of forming a continuous films i.e. around $8-10 \mathrm{~nm}$. This increase in EF enhancement follows 

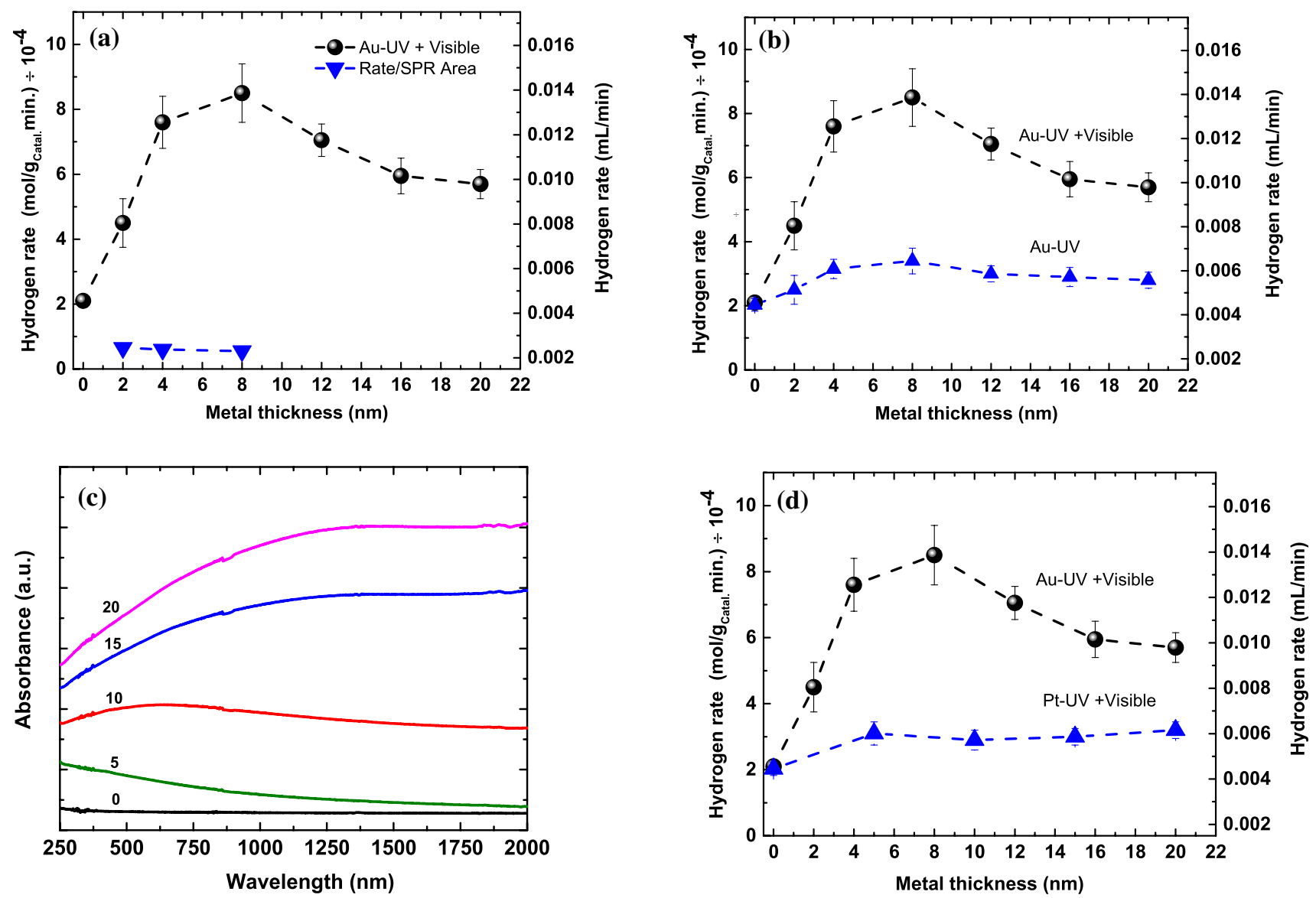

Fig. 3 a $\mathrm{H}_{2}$ production rates of 0.4 wt. $\% \mathrm{Pd} / \mathrm{TiO}_{2}$ photocatalyst as function of $\mathrm{Au}$ film thickness (spheres). $\mathrm{H}_{2}$ production rates normalized to SPR intensity as measured in UV-Vis absorption measurements (triangles). $\mathbf{b} \mathrm{H}_{2}$ production rates under $\mathrm{UV}$ and $\mathrm{UV}+$ visible light irradiation. UV flux was kept constant for both experiments. c

the trend seen in the photocatalytic $\mathrm{H}_{2}$ production activity. Both results show that with $8 \mathrm{~nm}$ Au thickness we get the largest enhancement. This is probably the first time that such a direct correlation has been observed between the EF enhancement and the photocatalytic activity for real $\mathrm{H}_{2}$ production. We have then normalized $\mathrm{H}_{2}$ production by $\mathrm{EF}$ enhancement. The straight line seen in Fig. 5b is akin to a turnover frequency in thermal catalytic reactions. In other words, for thermal reactions, involving a metal dispersed on a metal oxide support the rate can often be normalized to the amount of metal on top; this gives an intrinsic catalytic activity. It is shown here that the rate can be normalized to the collective field strength effect caused by the plasmonic metal underneath the catalyst. It is important to note that when we carried out the simulations at $350 \mathrm{~nm}$ we observed negligible differences between the EF enhancement from the different Au films as seen in Fig. 5a and Fig. S4 of the supplementary information.

UV-Vis-IR absorption spectra of Pt thin films with different thickness (in $\mathrm{nm}$ ) on quartz slides. $\mathbf{d ~} \mathrm{H}_{2}$ production of $0.4 \mathrm{wt} \% \mathrm{Pd} / \mathrm{TiO}_{2}$ photocatalyst as a function of metal ( $\mathrm{Au}$ or Pt) thickness. Reaction conditions Quartz reactor, Xenon lamp with UV flux (320$400 \mathrm{~nm}) \sim 12 \mathrm{~mW} / \mathrm{cm}^{2}, 30 \mathrm{~mL} \mathrm{H}_{2} \mathrm{O}$ with 5 vol\% glycerol

There have been several reports indicating that plasmonic photocatalytic enhancement occurs even in the presence of a $\mathrm{SiO}_{2}$ insulating layer between the plasmonic metal and the SC [19]. To further investigate this, we deposited thin $\mathrm{SiO}_{2}$ layers on top of $4 \mathrm{~nm}$ Au thin film using PECVD. Figure 6a shows a red shift of the plasmon peak upon coating with a $\mathrm{SiO}_{2}$ film. Increasing the effective permittivity causes a redshift in the LSPR wavelength. Comsol simulations shows that the EF enhancement at the $\mathrm{TiO}_{2}$ particle interface drops sharply with a $\mathrm{SiO}_{2}$ interlayer (inset of Fig. 6b). The $\mathrm{H}_{2}$ production activity of $\mathrm{Pd} / \mathrm{TiO}_{2}$ photocatalyst coated over $\mathrm{SiO}_{2}$-Au layer also drops drastically as a function of $\mathrm{SiO}_{2}$ thickness and reaches the original production rate (without $\mathrm{Au}$ thin film) upon using a $10 \mathrm{~nm}$ thick $\mathrm{SiO}_{2}$ layer. The drop in $\mathrm{H}_{2}$ rates follows the same trend as the drop in EF enhancement. The simulated $\mathrm{EF}$ (XY plane) without and with $5 \mathrm{~nm} \mathrm{SiO} \mathrm{S}_{2}$ layer on top of $4 \mathrm{~nm}$ Au thin film is shown in Fig. 6c, d respectively. The 

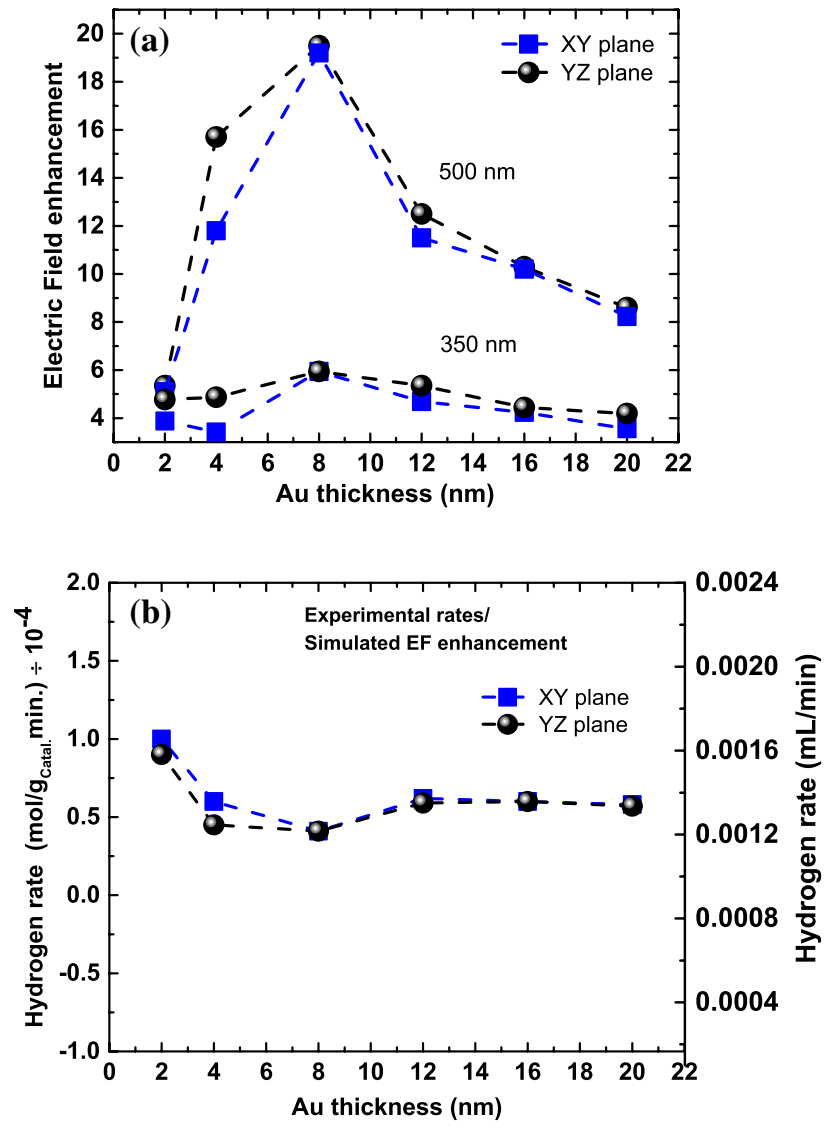

Fig. 4 Optical simulations of $\mathrm{TiO}_{2}$ on Au films. The incident electromagnetic $(E M)$ field $=1 \mathrm{~V} / \mathrm{m}$, with wavelength of incident EM field set to be at $500 \mathrm{~nm}$ and polarized in the y-direction. The XY-plane shows the EF enhancement at the boundary between $\mathrm{TiO}_{2}$ nanoparticles (NPs) and Au films while YZ-plane shows the EF enhancement along the $\mathrm{TiO}_{2}$-Au films-glass substrate

results with different thickness of $\mathrm{SiO}_{2}$ layer are reported in figure $\mathrm{S} 2$ of the supplementary information.

Based on the above results, we now may make an assessment of the role of plasmonics in photoreaction for $\mathrm{H}_{2}$ production. It is worth however, presenting, first, the different proposed mechanisms for this process to occur.

Direct hot electron transfer (DET) which results from the non-radiative damping (Landau damping) of LSPR. The plasmon-induced EF can create higher energy electrons via intraband (within sp band of $\mathrm{Au}$ ) or interband transitions. (d-sp band) [20]. In 2004, Tatsuma's group observed an increase in photon-to-current conversion efficiency (IPCE) under visible light illumination upon loading $\mathrm{Au}$ or $\mathrm{Ag}$ nanoparticles into $\mathrm{TiO}_{2}$ sol gel films $[5,6]$. In their proposed "charge transfer" mechanism, the LSPR excites electrons in $\mathrm{Au}$ or $\mathrm{Ag}$, which are then transferred to the conduction band of the adjacent $\mathrm{TiO}_{2}$. The system requires a redox couple such as $\mathrm{I}^{-} / \mathrm{I}_{3}{ }^{-}$or $\mathrm{Fe}^{2+} / \mathrm{Fe}^{3+}$ for electron donation to the metal. Furube et al. have also investigated the hot electron transfer via femtosecond transient absorption spectroscopy and observed electron injection from $\mathrm{Au}$ into $\mathrm{TiO}_{2}$ within 240 fs [21]. Subsequently, several other groups used this mechanism to explain enhanced photocatalytic water splitting, [8] methyl orange decomposition, [22] and photo-oxidation of formaldehyde [23]. While this charge transfer mechanism has been cited by many groups, it is understood that efficient generation of hot electrons with large energies appears only in small nanocrystals with dimensions below $20 \mathrm{~nm}$ and that the generation efficiency decreases with increasing size of Au nanoparticles [20]. Our experiments show increased activity from 2 to $8 \mathrm{~nm} \mathrm{Au}$ films where the particle size increases from $\sim 13.5$ to $\sim 45 \mathrm{~nm}$ (Fig. 2), indicating that hot electrons may not the major contributor to enhanced photocatalytic activity.

Cushing et al. have proposed plasmon induced resonant energy transfer (PIRET) which describes the non-radiative transfer of energy from the LSPR dipole of the metal to the transition dipole of the SC $[2,19]$. In other words, the strong local EM field of the LSPR can preferentially relax by exciting an electron hole pair in the SC without the emission of a photon. The strength of PIRET depends on the overlap of the SC band edge (absorption band) with the LSPR resonance band, as well as the distance between the two dipoles (the plasmonic metal and the SC). This is not the case for $\mathrm{Au}$ and $\mathrm{TiO}_{2}$ systems. Moreover, our studies show that as a function of increasing Au thickness there is a red shift of the plasmon absorbance i.e. any possible overlap between the $\mathrm{TiO}_{2}$ absorbance and plasmon absorbance decreases. Actually, for the $8 \mathrm{~nm}$ layer, the one showing largest effect on reaction rate has a LSPR at $\sim 2 \mathrm{eV}$ while the band gap of $\mathrm{TiO}_{2}$ may extend upto $3 \mathrm{eV}$. Unless one can invoke defects driven excitation levels, it is unclear how $\mathrm{Au}$ can contribute into band gap excitation of $\mathrm{TiO}_{2}$ following PIRET. Therefore, the present data indicates that PIRET does not lead to increased photocatalytic activity in the $\mathrm{Au}$ thin film- $\mathrm{Pd} / \mathrm{TiO}_{2}$ catalyst system.

Plasmonic nanostructures have also been proposed to increase photocatalytic activity due to photonic enhancement. Metal nanoparticles exhibit excellent scattering efficiency which increases significantly for particles $>50 \mathrm{~nm}$ in size [18]. Scattering increases the average path length of photons and some of the photons that are not absorbed by the SC could be scattered by the plasmonic metal particles effectively giving those photons multiple passes through the SC. This is known as the far field scattering mechanism in which nanoparticles act as a nano-mirror, causing an enhancement of light absorption and results in an improvement of overall efficiencies $[18,24]$. There are two arguments against this within the results observed in this work. First, far field enhancement should occur even in the presence of thin $\mathrm{SiO}_{2}$ layer. Second, the scattered light is in the 

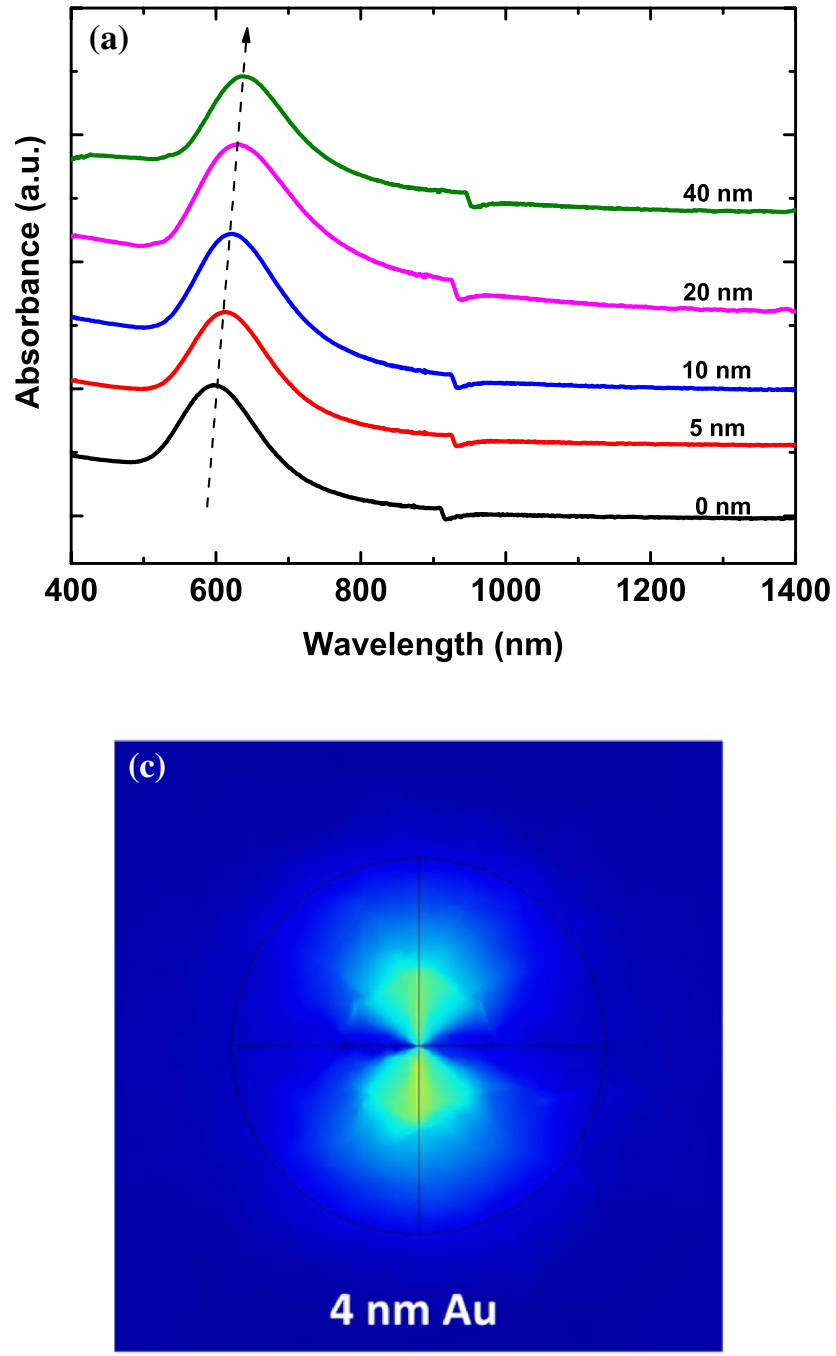

Fig. 5 a Simulated electric field (EF) enhancement at the $A u$ and $\mathrm{TiO}_{2}$ interface as a function of Au thickness in the $\mathrm{XY}$ and $\mathrm{YZ}$ planes (squares and spheres) for the 500 and $350 \mathrm{~nm}$ wavelengths. b $\mathrm{H}_{2}$ pro-

visible region $(500-700 \mathrm{~nm})$, which is poised to work for low band gap semiconductors and not $\mathrm{TiO}_{2}$.

The photocatalytic activity may also be enhanced due to the strong LSPR-induced EF at the metal-SC interface i.e., near field mechanism. High electron hole recombination rates are the primary reason for poor efficiency of most photocatalysts. The rate of electron-hole recombination in a semiconductor is influenced by the local electric field $[25,26]$. Thus, in regions of the semiconductor experiencing strong LSPR fields from the plasmonic metal, the rate of electron-hole recombination can decrease by a few orders of magnitude depending on the intensity of the electric field and thus increase the number of charge carriers available to carry out redox reactions [27]. The possibility of local EF enhancement in enhancing the photocatalytic activity has been studied by various groups earlier. Awazu

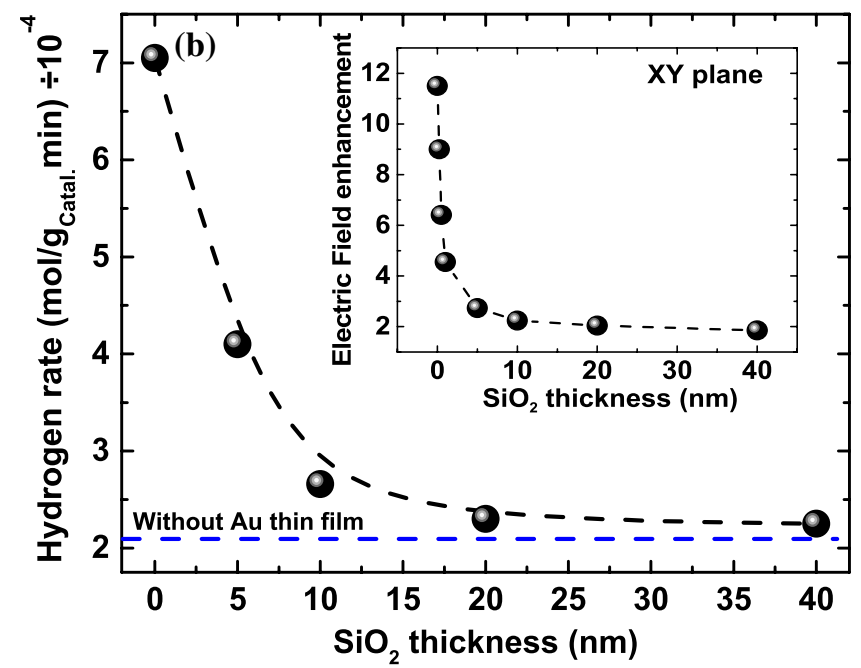

20
18
16
14
12
10
8
6
4
2
0

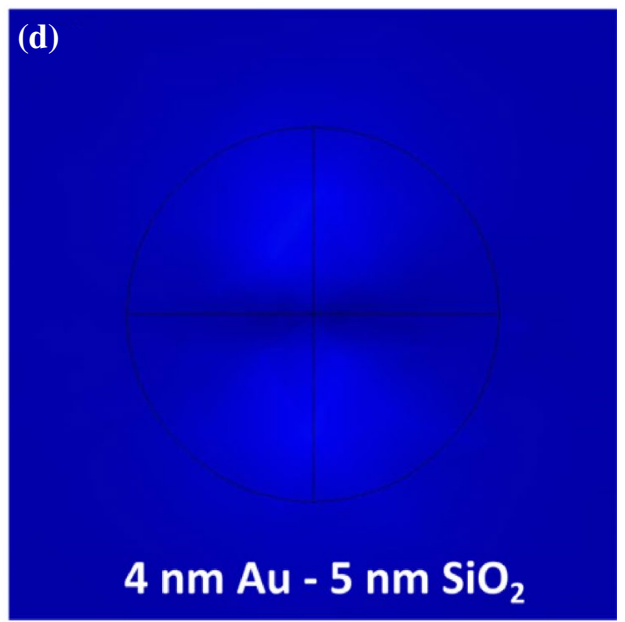

duction rates normalized to the $\mathrm{EF}$ enhancement at $500 \mathrm{~nm}$ obtained from optical simulations

and co-workers studied the photocatalytic behavior of $\mathrm{TiO}_{2}$ film coated on silica covered Ag NPs. They found that the photocatalytic efficiency of methylene blue dye degradation increased with a decrease in $\mathrm{SiO}_{2}$ layer thickness [28]. Cronin's group has attributed photocatalytic enhancement of both water splitting and dye degradation activity to this plasmonic local EF enhancement [29, 30]. Several other groups have also adopted the local EF enhancement mechanism [18, 30-33]. Time resolved spectroscopy studies of $\mathrm{TiO}_{2}$ have shown that charge carriers recombination rate takes place in time scales of about 10 ps to $1 \mathrm{~ns}$, [34, 35] while the frequency of resonant oscillation of free electrons in our Au films is in the range of $480-510 \mathrm{THz}$ (i.e. $2 \mathrm{fs}$ ). This is on a time scale much faster than the recombination rates in $\mathrm{TiO}_{2}$. The intensity of the electric field generated by the oscillation of these free electrons depends on the shape 


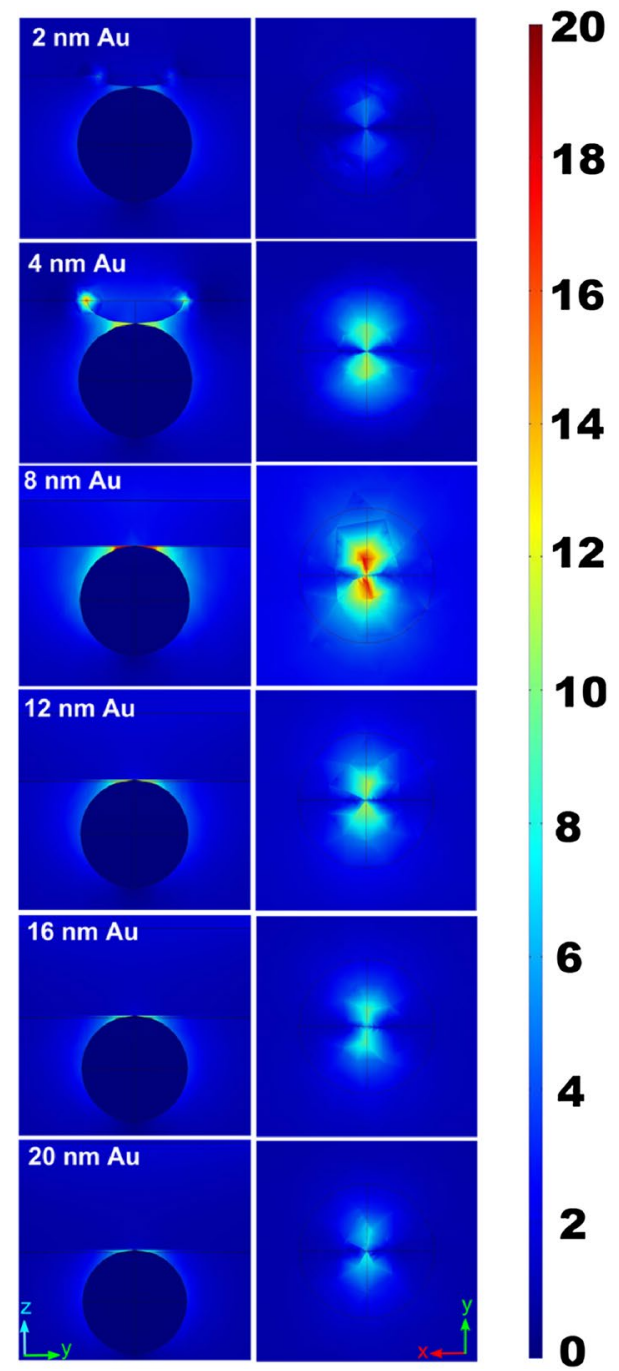

Fig. 6 a UV-Vis-IR absorption spectra of $4 \mathrm{~nm}$ Au thin film with $\mathrm{SiO}_{2}$ coating of different thickness. b $\mathrm{H}_{2}$ production rates of $0.4 \mathrm{wt} \%$ $\mathrm{Pd} / \mathrm{TiO}_{2}$ coated on $4 \mathrm{~nm} \mathrm{Au}-\mathrm{SiO}_{2}$ films as a function of $\mathrm{SiO}_{2}$ thickness. Inset shows simulated EF enhancement at the interface of $\mathrm{TiO}_{2}$ (XY plane) on top of $4 \mathrm{~nm} \mathrm{Au}-\mathrm{SiO}_{2}$ films as function of $\mathrm{SiO}_{2}$ thickness. c Simulated EF ( $X Y$ plane $)$ at the interface of $\mathrm{TiO}_{2}$ on top of $4 \mathrm{~nm}$ Au thin film. d Simulated EF (XY plane) at interface of $\mathrm{TiO}_{2}$ on top of $5 \mathrm{~nm} \mathrm{SiO} / 2 / 4 \mathrm{~nm}$ Au thin film

of the plasmonic particle as well as their inter-distance. As mentioned above with increasing thickness of Au film from 2 to $8 \mathrm{~nm}$ the inter-particle distance decreases and also their shape becomes more elongated both of which are known to amplify the electric field [36]. In regions between two Au particles, the EF is enhanced significantly as seen in our optical simulations. $\mathrm{TiO}_{2}$ particles at the interface with Au particles and in these hot spot regions experience strong LSPR fields poised to reduce the electron-hole pair recombination significantly. This mechanism seems to be the most plausible one for the results obtained in this work.

\section{Conclusions}

To conclude, $\mathrm{Pd} / \mathrm{TiO}_{2}$ over ultra-thin $\mathrm{Au}$ films were prepared and tested as model photocatalytic materials for $\mathrm{H}_{2}$ production, to decouple Schottky from plasmonic effects. The maximum rate enhancement $(4 \mathrm{x})$ was seen at the cusp of forming a continuous film at $\sim 8 \mathrm{~nm}$ thickness Au film above which the reaction rates decreased. The increase of the activity tracks the increase of the plasmonic response and the subsequent decrease tracks that of Drude absorption, as a clear evidence of plasmonic to non-plasmonic transition. Modelling of optical properties further confirmed the increase in reaction rates as due to $\mathrm{EF}$ enhancement. Coating thin interlayers of $\mathrm{SiO}_{2}$ between the Au layer and the catalyst exponentially decreased the catalytic performance. The results combined point to a local EF enhancement effect as the most tangible mechanism although "hot electron" injection into the $\mathrm{CB}$ of $\mathrm{TiO}_{2}$ cannot be ruled out. It is important to note that the high rate obtained is primarily limited to the plasmon effect which extends to a few tens of nm at the most. In other words, only a small fraction of the catalyst is seeing the effect. The challenge now is to make a catalytic systems where all materials absorb light and are all affected by the EF enhancement due to plasmonic material.

Open Access This article is distributed under the terms of the Creative Commons Attribution 4.0 International License (http:// creativecommons.org/licenses/by/4.0/), which permits unrestricted use, distribution, and reproduction in any medium, provided you give appropriate credit to the original author(s) and the source, provide a link to the Creative Commons license, and indicate if changes were made.

\section{References}

1. Fujishima A, Honda K (1972) Photolysis-decomposition of water at the surface of an irradiated semiconductor. Nature 238:37-38

2. Cushing SK, Wu N (2013) Plasmon-enhanced solar energy harvesting. Interface 22:63-67

3. Hou W, Cronin SB (2013) A review of surface plasmon resonance-enhanced photocatalysis. Adv Funct Mater 23:1612-1619

4. Xuming Z, Yu Lim C, Ru-Shi L, Din Ping T (2013) Plasmonic photocatalysis. Rep Progress Phys 76:046401

5. Tian Y, Tatsuma T (2004) Plasmon-induced photoelectrochemistry at metal nanoparticles supported on nanoporous $\mathrm{TiO}_{2}$. Chem Commun 16:1810-1811

6. Tian Y, Tatsuma T (2005) Mechanisms and applications of plasmon-induced charge separation at $\mathrm{tio}_{2}$ films loaded with gold nanoparticles. J Am Chem Soc 127:7632-7637

7. Rosseler O, Shankar MV, Du MK-L, Schmidlin L, Keller N, Keller V (2010) Solar light photocatalytic hydrogen production from water over $\mathrm{Pt}$ and $\mathrm{Au} / \mathrm{TiO}_{2}$ (anatase/rutile) photocatalysts: influence of noble metal and porogen promotion. J Catal 269:179-190 
8. Gomes Silva C, Juárez R, Marino T, Molinari R, García H (2011) Influence of excitation wavelength (UV or Visible Light) on the photocatalytic activity of titania containing gold nanoparticles for the generation of hydrogen or oxygen from water. J Am Chem Soc 133:595-602

9. Liu X, Wu B, Zhang Q, Yip JN, Yu G, Xiong Q, Mathews N, Sum TC (2014) Elucidating the localized plasmonic enhancement effects from a single $\mathrm{Ag}$ nanowire in organic solar cells. ACS Nano 8:10101-10110

10. Chen, WT, Chan A, Al-Azri ZHN, Dosado AG, Nadeem MA, Sun-Waterhouse D, Idriss H, Waterhouse GIN (2015) Effect of $\mathrm{TiO}_{2}$ polymorph and alcohol sacrificial agent on the activity of $\mathrm{Au} / \mathrm{TiO}_{2}$ photocatalysts for $\mathrm{H}_{2}$ production in alcohol-water mixtures. J Catal 329:499-513

11. Al-Azri ZHN, Chan A, Chen WT, Ina T, Idriss H, Waterhouse GIN (2015) On the role of metals and reaction media in photocatalysis for hydrogen production. Performance evaluation of $\mathrm{M} /$ $\mathrm{TiO}_{2}$ photocatalysts $(\mathrm{M}=\mathrm{Pd}, \mathrm{Pt}, \mathrm{Au})$ for $\mathrm{H}_{2}$ Production in different alcohol-water mixtures. J Catal 329:355-367

12. Sinatra L, LaGrow AP, Peng W, Kirmani AR, Amassian A, Idriss $\mathrm{H}$, Bakr OM (2015) $\mathrm{Au} / \mathrm{Cu}_{2} \mathrm{O}-\mathrm{TiO}_{2}$ system for photo-catalytic hydrogen production. A pn-junction effect or a simple case of in situ reduction? J Catal 322:109-117

13. Bowker M, Bahruji H, Kennedy J, Jones W, Hardley G, Morton C (2015) The photocatalytic window photo-reforming of organics and water splitting for sustainable hydrogen production. Catal Lett 145:214-219

14. Bowker M, Morton C, Kennedy J, Bahruji H, Greves J, Jones W, Davies PR, Brookes C, Wells PP, Dimitratos N (2015) Hydrogen production by photoreforming of biofuels using $\mathrm{Au}, \mathrm{Pd}$ and $\mathrm{Au}-$ $\mathrm{Pd} / \mathrm{TiO}_{2}$ photocatalysts. Catal Lett 145:214-219

15. Kaiser N (2002) Review of the fundamentals of thin-film growth. Appl Opt 41:3053-3060

16. Gong J, Dai R, Wang Z, Zhang Z (2015) Thickness dispersion of surface plasmon of ag nano-thin films: determination by ellipsometry iterated with transmittance method. Scientific Rep 5:9279.

17. Linic S, Christopher P, Ingram DB (2011) Plasmonic-metal nanostructures for efficient conversion of solar to chemical energy. Nat Mater 10:911-921

18. Cushing SK, Li J, Meng F, Senty TR, Suri S, Zhi M, Li M, Bristow AD, Wu N (2012) Photocatalytic activity enhanced by plasmonic resonant energy transfer from metal to semiconductor. $\mathrm{J}$ Am Chem Soc 134:15033-15041

19. Govorov AO, Zhang H, Demir HV, Gun'ko YK (2014) Photogeneration of hot plasmonic electrons with metal nanocrystals: quantum description and potential applications. Nano Today 9:85-101

20. Furube A, Du L, Hara K, Katoh R, Tachiya M (2007) Ultrafast plasmon-induced electron transfer from gold nanodots into $\mathrm{TiO}_{2}$ nanoparticles. J Am Chem Soc 129:14852-14853
21. Yu J, Dai G, Huang B (2009) Fabrication and characterization of visible-light-driven plasmonic photocatalyst $\mathrm{Ag} / \mathrm{AgCl} / \mathrm{TiO}_{2}$ nanotube arrays. J Phys Chem C 113:16394-16401

22. Tang $\mathbf{J}$ (2010) Interaction between noble metal nanoparticles and light for contaminant decomposition. ChemSusChem 3:800-801.

23. Zhang X, Zhu Y, Yang X, Wang S, Shen J, Lin B, Li C (2013) Enhanced visible light photocatalytic activity of interlayerisolated triplex $\mathrm{Ag} @ \mathrm{SiO}_{2} @ \mathrm{TiO}_{2}$ core-shell nanoparticles. Nanoscale 5:3359-3366

24. Anger P, Bharadwaj P, Novotny L (2006) Enhancement and quenching of single-molecule fluorescence. Phys Rev Lett 96:113002

25. Lee J, Javed T, Skeini T, Govorov AO, Bryant GW, Kotov NA (2006) Bioconjugated $\mathrm{Ag}$ nanoparticles and CdTe nanowires: metamaterials with field-enhanced light absorption. Angew Chem Int Ed 45:4819-4823

26. Hu C (2010) Modern semiconductor devices for integrated circuits. Prentice Hall, Upper Saddle River

27. Awazu K, Fujimaki M, Rockstuhl C, Tominaga J, Murakami H, Ohki Y, Yoshida N, Watanabe TA (2008) Plasmonic photocatalyst consisting of silver nanoparticles embedded in titanium dioxide. J Am Chem Soc 130:1676-1680

28. Hou W, Liu Z, Pavaskar P, Hung WH, Cronin SB (2011) Plasmonic enhancement of photocatalytic decomposition of methyl orange under visible light. J Catal 277:149-153

29. Hou W, Hung WH, Pavaskar P, Goeppert A, Aykol M, Cronin SB (2011) Photocatalytic conversion of $\mathrm{CO}_{2}$ to hydrocarbon fuels via plasmon-enhanced absorption and metallic interband transitions. ACS Catal 1:929-936

30. Ingram DB, Christopher P, Bauer JL, Linic S (2011) Predictive model for the design of plasmonic metal/semiconductor composite photocatalysts. ACS Catal 1:1441-1447

31. Lu Y, Yu H, Chen S, Quan X, Zhao H (2012) Integrating plasmonic nanoparticles with $\mathrm{TiO}_{2}$ photonic crystal for enhancement of visible-light-driven photocatalysis. Environ Sci Technol 46:1724-1730

32. Zhu H, Ke X, Yang X, Sarina S, Liu H (2010) Reduction of nitroaromatic compounds on supported gold nanoparticles by visible and ultraviolet light. Angew Chem 122:9851-9855

33. Mohamed HH, Bahnemann DW (2012) The role of electron transfer in photocatalysis: fact and fictions. Appl Catal 128:91-104

34. Schneider J, Matsuoka M, Takeuchi M, Zhang J, Horiuchi Y, Anpo M, Bahnemann DW (2014) Understanding TiO2 photocatalysis: mechanisms and materials. Chem Rev 114:9919-9986

35. Link S, El-Sayed MA (2000) Shape and size dependence of radiative, non-radiative and photothermal properties of gold nanocrystals. Int Rev Phys Chem 19:409-453

36. Zou S, Schatz GC (2005) Silver nanoparticle array structures that produce giant enhancements in electromagnetic fields. Chem Phys Lett 403:62-67 